\title{
Ceramic Tile Grout Removal \& Sealing Using High Power Lasers
}

\author{
J. Lawrence *, L. Li * and J.T. Spencer ** \\ * Department of Mechanical Engineering, UMIST, Manchester, M60-1QD, UK. \\ ** Company Research Laboratory, BNFL, Springfield Works, Preston, Lancashire, PR4-0XJ, UK.
}

\begin{abstract}
$\underline{\text { ABSTRACT }}$
Work has been conducted using a Nd:YAG laser, a $\mathrm{CO}_{2}$ laser and a high power diode laser (HPDL) in order to determine the feasibility of removing contaminated tile grout from the void between adjoining vitrified ceramic tiles, and to seal the void permanently with a material having an impermeable surface glaze. Reported on in the paper are; the basic process phenomena, the process effectiveness, suitable vitrifiable material development, a heat affect study and a morphological and compositional analysis.
\end{abstract}

\section{INTRODUCTION}

Ceramic tiles are applied to the walls and floors in a multitude of places; from hospital operating theatres to industrial clean-rooms. A major difficulty with tiled surfaces is that contaminants can enter into, and exit a space via a tiled surface, through the porous tile grouts used to fill the void between adjoining tiles. The problem is compounded, as a result of the tile grouts porosity, by water, germs and other harmful agents, which have the ability to permeate into cavities behind the tiles, corroding the bonding agent used to fix the tile to the substrate, the substrate itself or even the ceramic tile. Moreover, the predominant problem with commercially available tile grouts is that over time they become contaminated, and have to be removed physically or mechanically; an arduous, ineffective and costly undertaking that is not only time consuming, but often results in damage to the tiles. A solution to these problems, covered in this paper, is the use of high power lasers to remove contaminated tile grout from the void between adjoining ceramic tiles, a non-contact process that not only leaves the tiles completely undamaged, but is more efficient and effective than the traditional methods currently used. A HPDL is also used to produce a tough, inexpensive seal in the void between adjoining vitrified ceramic tiles using an amalgamated ceramic and oxide compound, as well as an amorphous, crack-free surface glaze on the amalgamated compound seal using an enamel powder. Thus the tiles are sealed and welded together permanently, preventing any further contamination activity. Unlike many other reported laser sealing and laser enamel treatment processes [1-7] the glaze was produced in normal atmospheric conditions without any pre-heating of the enamel.

\section{TILE GROUT REMOVAL USING LASER BEAMS}

\subsection{Experimental Procedure}

A $2 \mathrm{~kW}$-cw Electrox $\mathrm{CO}_{2}$ laser, a $400 \mathrm{~W}$-pulsed Lumonics Nd:YAG laser and a $60 \mathrm{~W}$-cw Diomed HPDL were used to study the possibility of laser tile grout removal. The grout used for the experiments was the ubiquitous waterproof ready mixed coloured tile grout, used to grout most tiled surfaces. The ceramic tiles used were the UK standard $150 \times 150 \times 5 \mathrm{~mm}$ white vitrified ceramic tiles. For experimental purposes the ceramic tiles were cut into smaller pieces, $20 \times 20 \mathrm{~mm}$, and applied in pairs to a Portland cement substrate using the tile grout. The spacing between the vitrified edges of each tile pair was the industry recommended 
$2 \mathrm{~mm}$, and was filled with tile grout in the conventional way. The fixed ceramic tile pieces were then allowed to cure for two to five days prior to the experiments.

The waterproof ready mixed coloured tile grout is formulated from four main components; acrylic emulsion, limestone, dolomite and a cellulose substance. The actual bonding mechanism by which the grout adheres to the surfaces to which it is applied is mechanical, or more precisely hydraulic, and is achieved as a result of the acrylic emulsion hydraulically bonding to the surface [8]. The limestone and dolomite act as fillers and the cellulose substance is added basically to thicken the grout. Since the grout does not bond chemically, it is unable to withstand elevated temperatures. At temperatures above $200^{\circ} \mathrm{C}$ the grout will actually debond from the surface it is applied to [9], a temperature well below what is likely when the beams of the three lasers are incident upon a surface.

The laser processing experimental arrangement is shown in Figure 1, where a defocused laser beam was fired along a tile grout track by traversing the workpiece on a $\mathrm{CNC}$ table. The fumes produced were extracted with an close-up extraction system, whilst $20 \mathrm{l} / \mathrm{min}$ of coaxially blown argon assist gas was used to remove the tile grout debris.

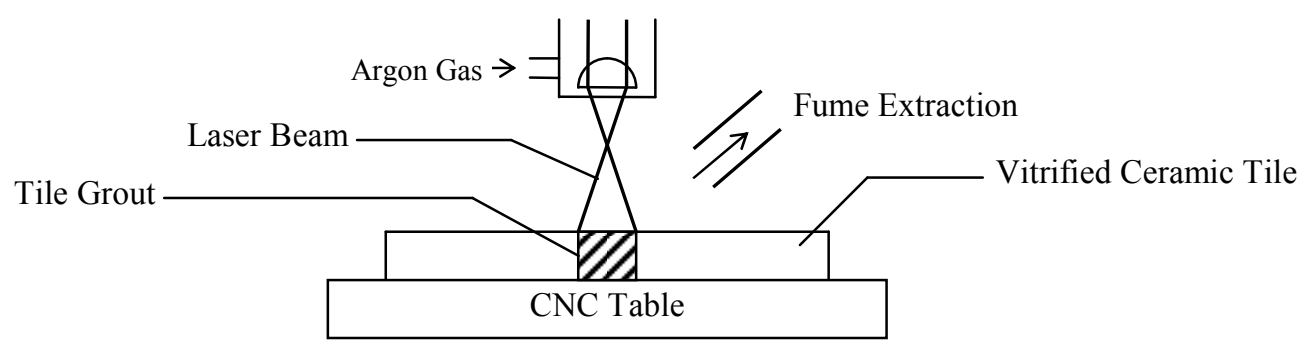

Figure 1: Schematic of laser tile grout removal experimental process arrangement.

\subsection{Experimental Results}

As Table 1 below shows, all three lasers were capable of successfully removing the vast majority of the waterproof ready mixed coloured tile grouting material with only one pass, at a range of output powers and scanning velocities.

Table 1 : Results of the laser tile grout removal experiments using the Electrox $2 \mathrm{~kW}-\mathrm{cw} \mathrm{CO}_{2}$ laser, the Lumonics JK704 $400 \mathrm{~W}$-pulsed Nd:YAG laser and the Diomed $60 \mathrm{~W}$-cw HPDL, white vitrified ceramic tiles and waterproof ready mixed coloured tile grout.

\begin{tabular}{|l|c|c|c|}
\hline Laser & $\mathrm{CO}_{2}$ & $\mathrm{Nd}: Y A G$ & HPDL \\
\hline Output Power & $80-150 \mathrm{~W}-\mathrm{cw}$ & $50-150 \mathrm{~W}-\mathrm{pulse}(2 \mathrm{~ms})$ & $40-60 \mathrm{~W}-\mathrm{cw}$ \\
\hline Spot Diameter & $3-5 \mathrm{~mm}$ & $4-5 \mathrm{~mm}$ & $2-3 \mathrm{~mm}$ \\
\hline Traverse Speed & $3-6 \mathrm{~mm} / \mathrm{s}$ & $2-10 \mathrm{~mm} / \mathrm{s}$ & $3-10 \mathrm{~mm} / \mathrm{s}$ \\
\hline$\%$ Volume Removed & $\sim 70-80 \%$ & $>90 \% *$ & $40 \%(50 \% *)$ \\
\hline
\end{tabular}

* Water film added prior to irradiation.

As one can see, the Nd:YAG laser removed a greater volume of the tile grout than either the $\mathrm{CO}_{2}$ laser or the HPDL. One probable reason for the removal capability difference between the three lasers may simply be that the Nd:YAG laser, because it can produce a high energy pulse, can deliver considerably more energy than the $\mathrm{CO}_{2}$ laser or the HPDL to the surface of the waterproof ready mixed coloured tile grout; a maximum of $1.5 \mathrm{~kW}$ in each $2 \mathrm{~ms}$ pulse for the same average power.

Another, perhaps more important output wavelength related aspect of the laser tile grout removal process, is that both the Nd:YAG laser and the HPDL were capable of removing the tile grout whilst leaving the tiles 
undamaged, regardless of the output power, the spot size or the tile colour. When removal was attempted using the $\mathrm{CO}_{2}$ laser at output powers in excess of $80 \mathrm{~W}$, for all spot sizes, damage to the tile edges in contact with the tile grout, and to the top surfaces adjacent to the edges to a width of 0.5 to $2 \mathrm{~mm}$, was clearly visible. The damage was in the form of melting of the vitrified surface of the tile. The reason for this difference in the tile condition after irradiation can only be explained by the difference in wavelength magnitude between the short wavelength lasers, the Nd:YAG $(1.06 \mu \mathrm{m})$ and the HPDL $(0.81 \mu \mathrm{m} \pm 0.02 \mu \mathrm{m})$, and the long wavelength $\mathrm{CO}_{2}(10.6 \mu \mathrm{m})$ laser. Clearly, the tile surface reflects more of the shorter wavelength Nd:YAG and HPDL radiation, whilst absorbing considerably more of the longer wavelength $\mathrm{CO}_{2}$ radiation.

\section{$\underline{2.3 \text { Discussion }}$}

Visual inspections of the experimental samples carried out during and after the laser tile grout removal process indicate that the area of grout on which the output beam is incident is rapidly, almost instantaneously fragmented and ejected. This violent fragmentation of the irradiated section of grout can only be due to the fact that the grout debonds at temperatures in excess of $200^{\circ} \mathrm{C}$ [9]. Since the temperature of the irradiated grout is well in excess of $200^{\circ} \mathrm{C}$, the result will be almost explosive debonding of the material, ejecting the debonded grout out of the area $[10,11]$.

Attempts to increase the tile grout removal rate of the Nd:YAG laser and the HPDL by adding a thin film of water to the surface of the tile grout prior to irradiation, proved to be fairly successful as Figure 2 shows. This is due to the fact that water is effectively transparent to short wavelength laser radiation $(<1.06 \mu \mathrm{m})$, thus, the high incident powers that give rise to the intense heating of the waterproof ready mixed coloured tile grout surface also cause the water at the surface/water interface to heat rapidly [12]. This leads to the explosive evaporation of the water, thereby exerting a momentum-transfer reactive force capable of mechanically damaging the surface of the waterproof ready mixed coloured tile grout $[13,14]$. Also, the explosive evaporation of water within the now damaged surface layer of the waterproof ready mixed coloured tile grout exerts large transient forces on the material sufficient to cause the ejection of the matter $[12,15]$.

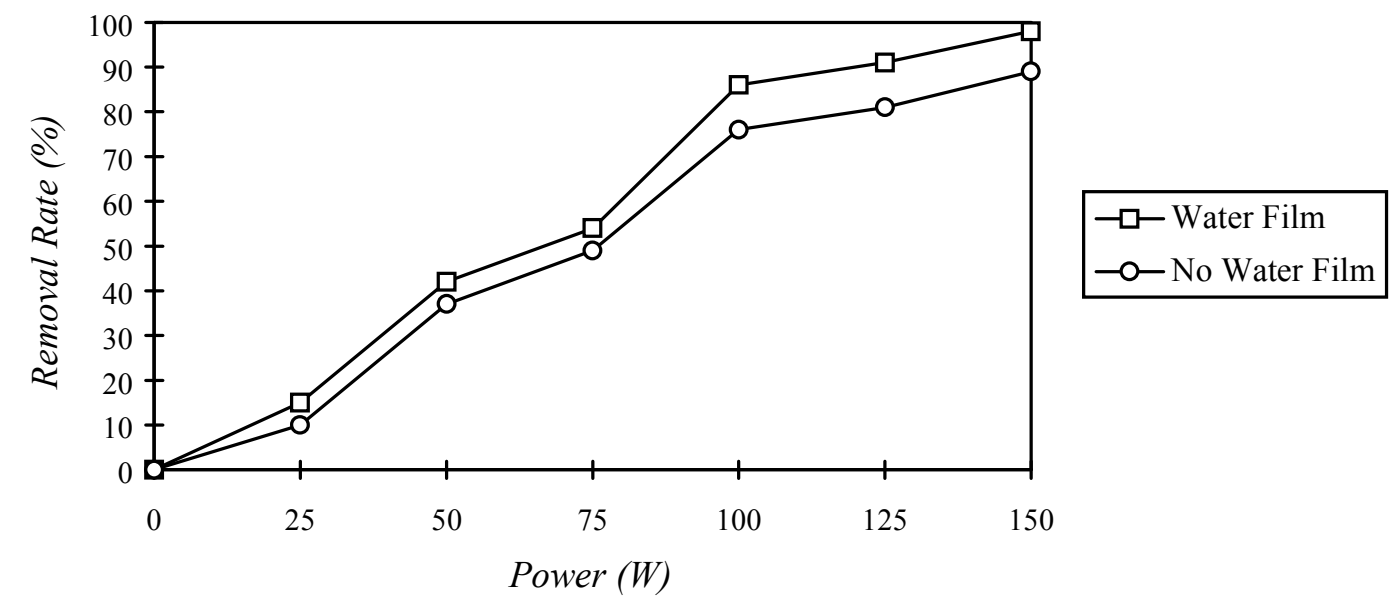

Figure 2: Variation in waterproof ready mixed coloured tile grout removal rate with laser output power (with and without water film) using the Lumonics JK704 $400 \mathrm{~W}$-pulsed Nd:YAG laser.

An analysis of the resultant process debris, with and without the water film, was carried out. By passing the collected debris through a series of mesh sieves the mean diameter of the ejected tile grout particles was determined to be between $80 \mu \mathrm{m}$ and $400 \mu \mathrm{m}$. When removal was carried out without the water film, the 
debris was in the form of a dust consisting of small particles which lay on and around the ceramic tiles. Removal with the water film resulted in a number of these small particles adhering loosely to the ceramic tile surface. However, this debris could simply be brushed off the ceramic tiles without any detrimental effect to the ceramic tile surface itself.

A post-process microscopic examination of the ceramic tile surface revealed a very narrow heat affected zone (HAZ) extending approximately $200 \mu \mathrm{m}$ from the edge of the tiles (Figure 3 ). This heat affected region was found to be the remelted vitreous (borosilicate glass) surface layer of the ceramic tiles, and as such, does not extend in depth beyond the $100 \mu \mathrm{m}$ thick vitrified borosilicate glass surface coating into the ceramic body of the tile.

Figure 3: Optical micrograph of ceramic tile edges showing narrow HAZ after waterproof ready mixed tile grout removal with Lumonics JK704 400 W-pulsed Nd:YAG laser (water film). Average output power $100 \mathrm{~W} @ 50 \mathrm{~Hz}$ with $2 \mathrm{~ms}$ pulse duration (1 kW peak), $2 \mathrm{~mm}$ spot diameter and $6 \mathrm{~mm} / \mathrm{s}$ traverse speed.

\section{CERAMIC TILE SEALING USING A HIGH POWER DIODE LASER}

\section{$\underline{3.1 \text { Experimental Procedure }}$}

Using the Diomed $60 \mathrm{~W}-\mathrm{cw}$ HPDL, research was conducted to determine the possibility of producing an impervious surface glaze on a variety of vitrifiable substances placed in the void between adjoining vitrified ceramic tiles, thus sealing and welding together the tiles permanently. The experiments were carried out using vitrified ceramic tiles of various colours; white, navy blue and jet black, cut into smaller pieces, $20 \times 20 \mathrm{~mm}$, for experimental purposes and applied in pairs to the substrate. The method of application and the substrate conditions were as before in the laser tile grout removal experiments. Figure 4 details the laser processing experimental arrangement, where a defocused laser beam was fired along the vitrifiable substances placed in the void between adjoining vitrified ceramic tiles by traversing the workpiece on a $\mathrm{CNC}$ table. The fumes produced were extracted with an extraction system, whilst $31 / \mathrm{min}$ of coaxially blown argon assist gas was used to shield the laser optics.

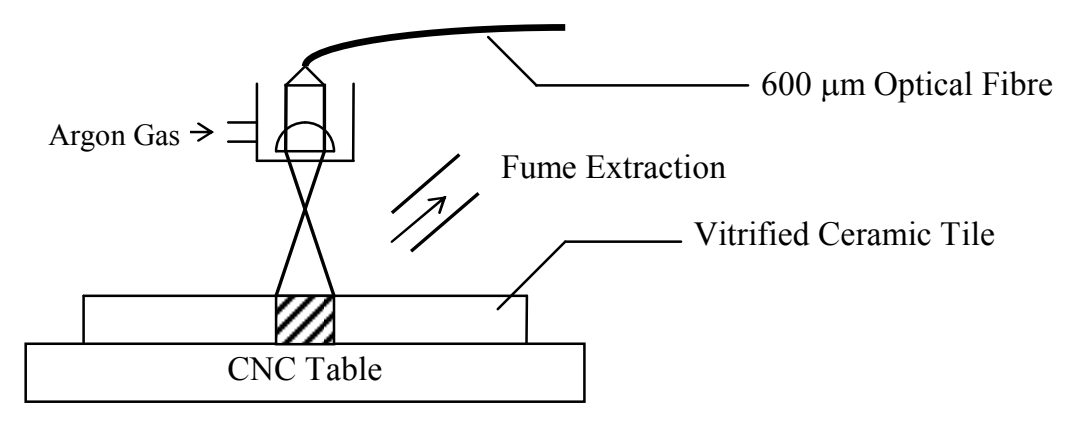




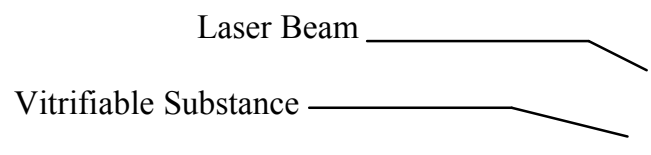

Figure 4: Schematic of laser ceramic tile sealing experimental process arrangement.

\subsection{Sealing Material Development}

Theoretical and experimental studies by previous workers $[16,17]$ established that glazing could only be achieved using materials containing at least some of the essential glass network forming compounds such as $\mathrm{SiO}_{2}$ and $\mathrm{BO}_{3}$, along with some glass network modifying and intermediate compounds such as $\mathrm{Na}_{2} \mathrm{O}, \mathrm{Al}_{2} \mathrm{O}$ and $\mathrm{MgO}$. Indeed, initial experiments conducted by the authors using such materials (vitrified ceramic tile powder and pyrex glass powder) resulted in reasonable quality seals being produced. However, surface microcracks and porosities were ever-present features of the glazes, and as such, rendered them unsound. Similarities in the results of this work are reflected by those of Shaw [18] and Fabes [19] who used laser radiation to densify sol-gel silica glass. Despite the fact that the laser densification of the sol-gel was successful, in terms of the speed of the process and the levels of densification achieved, surface porosities and microcracking always resulted.

This is perhaps to be expected, since under normal manufacturing conditions the glass is raised to its softening temperature and held there for many hours, not just for the few seconds it takes for the laser to pass across and irradiate the glass solution or the powders. Clearly the process was too rapid for the vitrified ceramic tile powder and the pyrex glass powder, resulting in surface microcracks and porosities. The surface microcracking was due, in part, to the solidified material over contracting as a result of the elevated melting temperatures caused by the high $\mathrm{SiO}_{2}$ content of the materials. However, the formation of microcracks was mainly due to excessive thermal stresses resulting from the greatly reduced heating/cooling cycle times which create a large thermal gradient between the melted region and the cooler surrounding material. The thermal stress, $\sigma$, induced by a thermal gradient can be calculated using the Kingery expression [20];

$$
\sigma=\frac{E \beta \Delta T}{1-v}
$$

$$
\text { where, } \quad \begin{aligned}
\mathrm{E} & =\text { Young's Modulus, } \mathrm{MN} / \mathrm{m}^{2} \\
\Delta \mathrm{T} & =\text { Thermal Gradient, } \mathrm{K} \\
\beta & =\text { Coefficient of thermal expansion, } \mathrm{K}^{-1} \\
v & =\text { Poisson's ratio }
\end{aligned}
$$

$\Delta \mathrm{T}$ is the difference between the critical temperature (below which stresses can no longer be relieved) and ambient temperature. For pyrex glass this is the difference between the softening point, $780^{\circ} \mathrm{C}$ and ambient temperature $20^{\circ} \mathrm{C}$. By using the following values for pyrex glass; $\mathrm{E}=6.42 \times 10^{4} \mathrm{MN} / \mathrm{m}^{2}, \beta=33 \times 10^{-7} \mathrm{~K}^{-1}$ and $\nu=0.176$, when the pyrex glass powder is irradiated by the laser beam the thermal stress produced according to Equation (1) is $185 \mathrm{MN} / \mathrm{m}^{2}$. Since this is in excess of the fracture strength of pyrex glass $\left(120 \mathrm{MN} / \mathrm{m}^{2}\right)$, cracking will occur, and can only be avoided by severe distortion or through the reduction of $\Delta \mathrm{T}$ by preheating.

The resultant porosities were due to either the materials lack of fluidity when melted, preventing bubbles from escaping the surface properly, or the lack within the materials composition of compounds such as $\mathrm{Fe}_{2} \mathrm{O}_{3}$ or $\mathrm{FeS}_{2}$ which are known to reduce the amount of oxygen released during reaction. 
Based on the results of this preliminary work, a series of laser ceramic tile sealing experiments were conducted using a variety of unmixed vitrifiable oxides. This work in turn led to experiments being carried out using amalgamated compounds of certain vitrifiable oxides, namely; pozzolana, chamotte, $\mathrm{Fe}_{2} \mathrm{O}_{3}, \mathrm{MgO}$, $\mathrm{ZrO}_{2}$ and $\mathrm{ZnO}$, in order to optimise the beneficial properties, and reduce the detrimental properties of the constituent materials. The selected compounds were thoroughly mixed together to ensure homogeneity, along with $\sim 50 \%$ water diluted sodium silicate solution (water glass) so as to form a manageable paste. The paste was then immediately applied into the void between adjoining tile pairs and, according to the findings of cursory experiments conducted to determine the optimum settling time, allowed to cure for two days prior to the experiments. Table 2 details the amalgamated compound composition that was found to give the optimum seal results and the characteristics that each compound imparts on the blend during laser irradiation.

Table 2 : Composition and basic functions of the optimum ceramic compounds and oxides mixture.

\begin{tabular}{|l|l|}
\hline Compound Composition & \multicolumn{1}{|c|}{ Characteristics } \\
\hline Chamotte & Consists mainly of $\mathrm{Al}_{2} \mathrm{O}_{3}, \mathrm{TiO}_{2}$ and $\mathrm{SiO}_{2}$. \\
\hline Iron Oxide $\mathrm{Fe}_{2} \mathrm{O}_{3}$ & $\begin{array}{l}\text { Reduces the amount of oxygen released during reaction and therefore reduces } \\
\text { the surface blistering and small porosities. }\end{array}$ \\
\hline Magnesia $\mathrm{MgO}$ & $\begin{array}{l}\text { Glass network modifier. Lowers the softening temperature. Reduces the number } \\
\text { of network bonds and therefore reduces the viscosity. Has a beneficial } \\
\text { stabilising effect. }\end{array}$ \\
\hline Zinc Oxide $\mathrm{ZnO}$ & $\begin{array}{l}\text { Imparts fluidity (reduces the viscosity) and ease of melting without effecting the } \\
\text { thermal expansion. Also increases the resistance to thermal shock. }\end{array}$ \\
\hline
\end{tabular}

Despite the fact that good quality seals could be produced using the amalgamated compound, a microscopic examination revealed the structure to be crystalline. Thus, such a seal would be unable to function correctly allowing water, germs or other harmful agents to permeate through its surface.

An amorphous surface layer on top of the amalgamated compound seal was achieved by applying approximately a $250 \mu \mathrm{m}$ layer of enamel to the seal surface. The composition of the enamel consisted mainly of the following; $\mathrm{SiO}_{2}, \mathrm{~B}_{2} \mathrm{O}_{3}, \mathrm{Na}_{2} \mathrm{O}, \mathrm{Mn}, \mathrm{F}$ and small quantities of $\mathrm{Ba}, \mathrm{Al}_{2} \mathrm{O}_{3}$ and $\mathrm{Ni}$, whilst the powder size was $<75 \mu \mathrm{m}$. In order to form a manageable paste the enamel was mixed with $20 \mathrm{wt} \%$ white spirit and applied to the surface of the seals and irradiated by the laser immediately.

Thus the sealing of the vitrified ceramic tiles is achieved by means of a two stage process, with the seal itself consisting of two distinct components; an amalgamated compound substrate and a glazed enamel surface. The amalgamated compound seal provides a tough bulk substrate which simply acts a filler for the void between adjoining tiles. The surface is laser treated so as to produce a smooth consolidated surface that will allow the adherence of the glazed enamel. The enamel glaze is bonded completely to the tiles as well as the laser treated surface of the amalgamated compound substrate, and as such provides an impervious surface.

\subsection{Experimental Results \& Discussion}

Figure 5(a) illustrates the operating window, in terms of traverse speed and laser power density, for the laser sealing process using the amalgamated compound detailed in Table 2. Within the optimum operating conditions good quality seals displaying very few microcracks and no porosities could be produced, with an average thickness of around $1.5 \mathrm{~mm}$. 

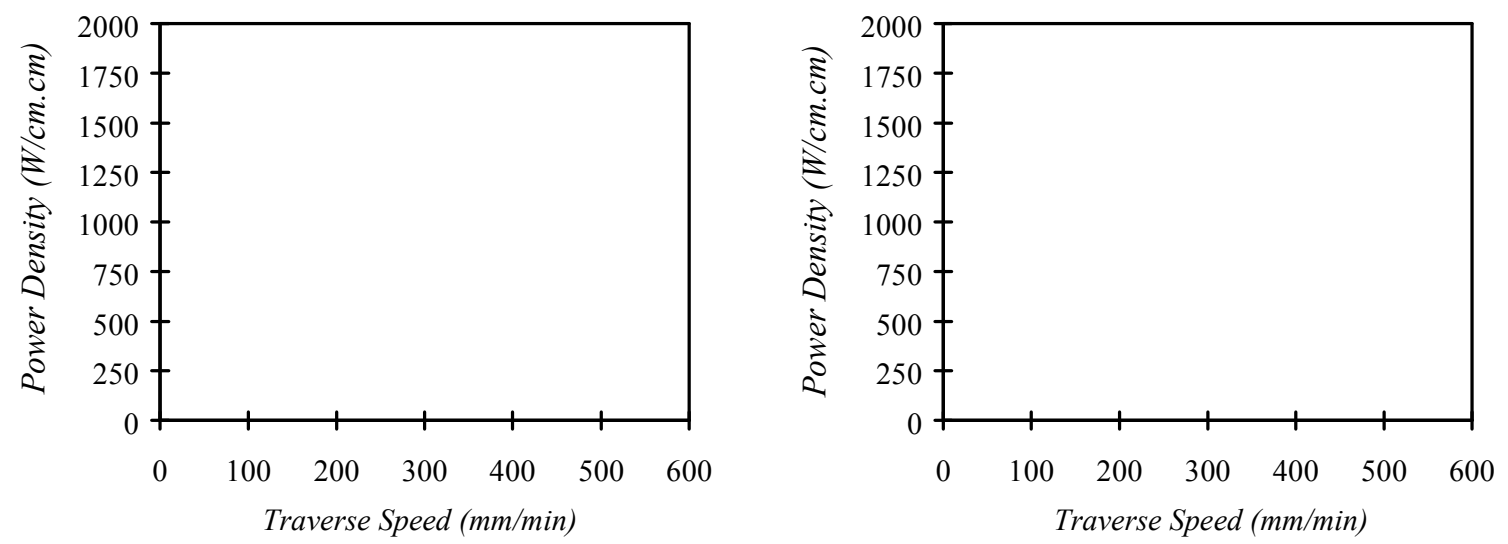

Figure 5: Schematic of operating window for, (a) laser ceramic tile sealing with an amalgamated compound and (b) seal glazing using enamel.

Figure 5(b) details the relationship between the traverse speed, the laser power density and the resultant condition of the glaze on the enamel surface. No exceptional atmospheric conditions or pre-heating were required to produce the glazes, which were completely free of microcracks and porosities as Figure 6(a) clearly shows.

Figure 6: SEM images of the surface of the tile/enamel glaze interface (a) and the cross-section of the amalgamated compound seal and the enamel surface glaze (b). Samples coated with Au film. Images obtained using a Jeol JSM330A SEM.

The major reason for the eradication of microcracks is the reduction in the thermal gradient, $\Delta \mathrm{T}$, during laser irradiation. This was due partly to the fact that the softening point of the enamel powder is $\sim 500^{\circ} \mathrm{C}$, much lower than many of the other materials tested. Therefore, according to Equation (1), the tensile stresses that result from the unrelieved elastic stresses that occur due to the contraction of the material between the softening point $\left(500^{\circ} \mathrm{C}\right)$ and ambient temperature $\left(20^{\circ} \mathrm{C}\right)$ are much reduced to a value below that 
of the fracture strength. Also, because the output beam from the HPDL is inherently non-Gaussian in nature, a temperature profile that peaks in the centre of the irradiated region and tapers off to room temperature at the circumference [3] is avoided. Thus, during cooling the contraction of any part is not opposed by the neighbouring elements, which are at different temperatures when a Gaussian beam is used. As such the resultant high radial, tangential and axial stresses are greatly reduced.

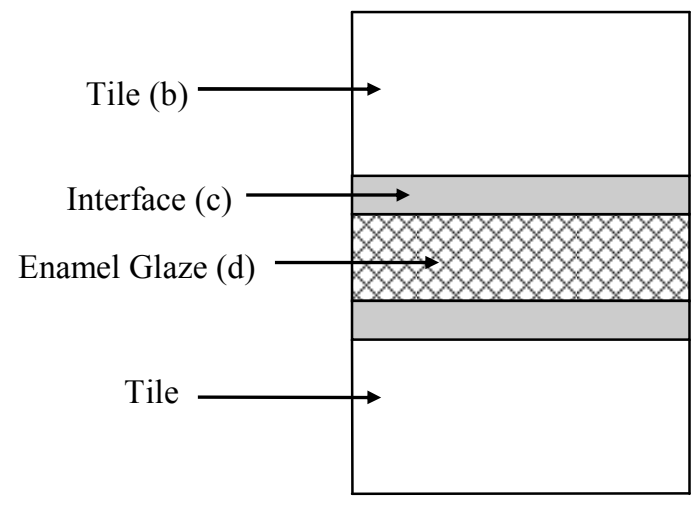

Figure 7: Schematic plan view of a laser glazed enamel seal (a) showing the respective EDAX analysis areas. EDAX analysis reading for the tile surface (b), the tile/enamel glaze interface (c) and the enamel glaze surface (d).

An EDAX analysis at the various positions indicated in Figure 7(a) indicated the presence within the region of elements unique to the borosilicate glass tile surface ( $\mathrm{Zn}, \mathrm{Co}, \mathrm{Ba}$, etc.), and the enamel ( $\mathrm{Ti}, \mathrm{Mn}$, etc..), 
confirming that dilution between the enamel glaze and the borosilicate glass surface of the tiles had occurred. Since there are no cracks or porosities in the enamel glaze or the interface between the enamel glaze and the borosilicate glass tile surface (Figure 6(a)), it is reasonable to assume that a continuous impervious surface has therefore been created across the surface of the tiles and the seal.

From Figure 6(a) the narrow HAZ is clearly visible, measuring around $100 \mu \mathrm{m}$ in width. As with the tile grout removal process, the heat affected region is in the form of the remelted borosilicate glass surface layer of the ceramic tiles. However, the extent of this remelting, in terms of depth and magnitude, is much less than that experienced during tile grout removal. Along the tile/enamel glaze interface a narrow region of dilution between the borosilicate glass surface layer and the enamel glaze, which extends from the interface across the tile, is clearly visible (Figure 6(a)). Also, as Figure 6(b) shows, not only has dilution occurred between the tile and the enamel glaze, but also between the enamel glaze and the laser treated surface of the amalgamated compound seal, indicating that a fusion bond has been created.

\section{CONCLUSION}

The removal of waterproof ready mixed coloured tile grout has been successfully demonstrated with average output powers ranging from 40-150 W using a $\mathrm{CO}_{2}$ laser, a Nd:YAG laser and a HPDL. The Nd:YAG laser proved to be far superior; being capable of removing in excess of $90 \%$ of the tile grout without damaging the vitrified ceramic tiles. It was also found that the application of a thin water film to the surface of the tile grout prior to irradiation resulted in $\sim 10 \%$ increase in the removal rate.

Vitrified ceramic tiles of various colours have been successfully sealed with power densities as low as $500 \mathrm{~W} / \mathrm{cm}^{2}$ and at rates as high as $600 \mathrm{~mm} / \mathrm{min}$. A complete fusion bond between the amorphous enamel glaze and the tiles, as well as the amalgamated compound substrate, was achieved, whilst the enamel glaze itself was free of cracks and porosities. The low softening temperature of the enamel, and the subsequent reduction in the thermal gradient during irradiation, combined with the inherent non-Gaussian nature of the HPDL output allowed the generation of an impervious surface enamel glaze without the need for exceptional atmospheric conditions or pre-heating.

\section{ACKNOWLEDGEMENTS}

The authors would like to express their gratitude to the EPSRC: Process Engineering Group (Grant No. GR/K99770), the EPSRC: CDP Group (CASE Award No. 95562556) and BNFL (BNFL Agreement No. A751688) for their financial support. Also, many thanks go to Carol Duckworth and Carl Hogarth of BNFL, Springfield Works and Max Richens of Vitreous Enamels Ltd. for sharing their time and expertise. The authors are also grateful to the University of Liverpool for allowing them to use their $\mathrm{CO}_{2}$ and $\mathrm{Nd}: Y A G$ lasers during the early stages of the work.

\section{REFERENCES}

1. Adamski, A., McPherson, R., (1986), "Laser Sealing of Ceramic Surface Layers", Proceedings of the $11^{\text {th }}$ International Thermal Spraying Conference, May 1986, Los Angeles, CA., p 555.

2. Mordike, B.L., Sivakumar, R., (1986), "Laser Surface Melting of $\mathrm{ZrO}_{2}$ Protective Layers", Proceedings of ECLAT '86, May 1986, Berlin, Germany, p 373-381.

3. Sivakumar, R., Mordike, B.L., (1988), “Laser Melting of Plasma Sprayed Ceramic Coatings”, Journal of Surface Engineering, Feb. 1988, Vol 4 (2), p 127-140.

4. Liu, Z., (1991), "Surface Modification of Materials Using High Power Lasers and an Arc Image Intensifier", PhD Thesis, University of Liverpool. 
5. Yu, J., Wu, W., Wang, M., (1993), "Preparation of Enamel Coating by Laser Irradiation", Chinese Journal of Lasers, Aug. 1993, Vol B2 (4), p 377-383.

6. Buerhop, C., WeiBmann, R., (1995), "Enamelling of Glass by $\mathrm{CO}_{2}$ Laser Treatment", Glass Science \& Technology, May 1995, Vol 68 (5), p 147-152.

7. Wang, M., Yu, J., Chen, J., Wu, W., (1995), "Laser Cladding of Oxide-Ceramic Powder With Enamel Frit on a Steel Substrate", Proceedings of ICALEO '95: Laser Materials Processing, Nov. 1995, San Diego, CA., Vol 80, p 699-709.

8. Allyn, G., (1957), Basic Concepts of Acrylic Emulsion Paint Technology, Rohm \& Haas Company, Philadelphia, PA.

9. Quinn, T.J., (1985), Polymers Paint Colour Yearbook, FMJ Publications Ltd., London.

10. Dabby, F.W., Peak, U.C., (1971), ), "High Intensity Laser-Induced Vaporisation and Explosion of Solid Material", IEEE Journal of Quantum Electronics, June 1971, Vol 7 (6), p 276.

11. Andrews, J.G., Atthey, D.R., (1976), ), "Hydrodynamic Limit to Penetration of an Explosion of Solid Material", Journal of Physics D: Applied Physics, Oct. 1976, Vol 9 (10), p 2181-2194.

12. Cooper, M.I., Emmony, D.C., Larson, J., (1995), "Characterisation of Laser Cleaning of Limestone", Optics \& Laser Technology, Jan. 1995, Vol 27 (1), p 69-73.

13. Scrubby, L.B., Drain, L.E., (1990), Laser Ultrasonics, Adam Hilger Publishers, Bristol.

14. Tam, A.C., Leung, W.P., Zapica, W., Ziemlich, W., (1992), ), "Laser Cleaning Techniques for the Removal of Surface Particulates", Journal of Applied Physics, May 1992, Vol 8 (71), p 3515-3523.

15. Sugimoto, K., Wignarajah, S., Nagasi, K., Yasu, S., (1990), "Fundamental Study on Laser Treatment of Architectural Materials", Proceedings of ICALEO '90: Laser Materials Processing, Nov. 1990, Boston, MA., Vol 71, p 302-312.

16. Morey, G.W., (1954), The Properties of Glass, Von Nostrad Reinhold Ltd., New York, NY.

17. Doremus, R.H., (1994), Glass Science, John Wiley \& Sons Inc., New York, NY.

18. Shaw, D.J., (1990), "Laser Densification and Laser Host Properties of Sol-Gel Silica Glass", $\mathrm{PhD}$ Thesis, University of Manchester.

19. Fabes, B.D., (1994), "Laser Processing of Sol-Gel Coatings", in Sol-Gel Optics: Processing and Applications, Eds: L.C. Klein, Kluwer Academic Publishers, Norwell, MA., p 483-510.

20. Jeandin, M., Albert, D., Martinou, R., Lechervy, P., Varela, D., (1988), "Laser Treatment of PlasmaSprayed Ceramic Coatings", Proceedings of the $4^{\text {th }}$ International Colloquium on Welding and Melting by Electrons and Laser Beams, Sep. 1988, Paris, France, p 47-56.

Mr. Jonathan Lawrence graduated from the University of Bradford in 1994 with an honours degree in Mechanical Engineering. He has just completed the first year of a PhD project to study the feasibility of high power diode laser materials processing. Dr. Lin Li is head of the Laser Laboratory and a lecturer at UMIST. Dr. Julian Spencer is a Senior Research Associate, managing laser projects at the BNFL Company Research Laboratory. 